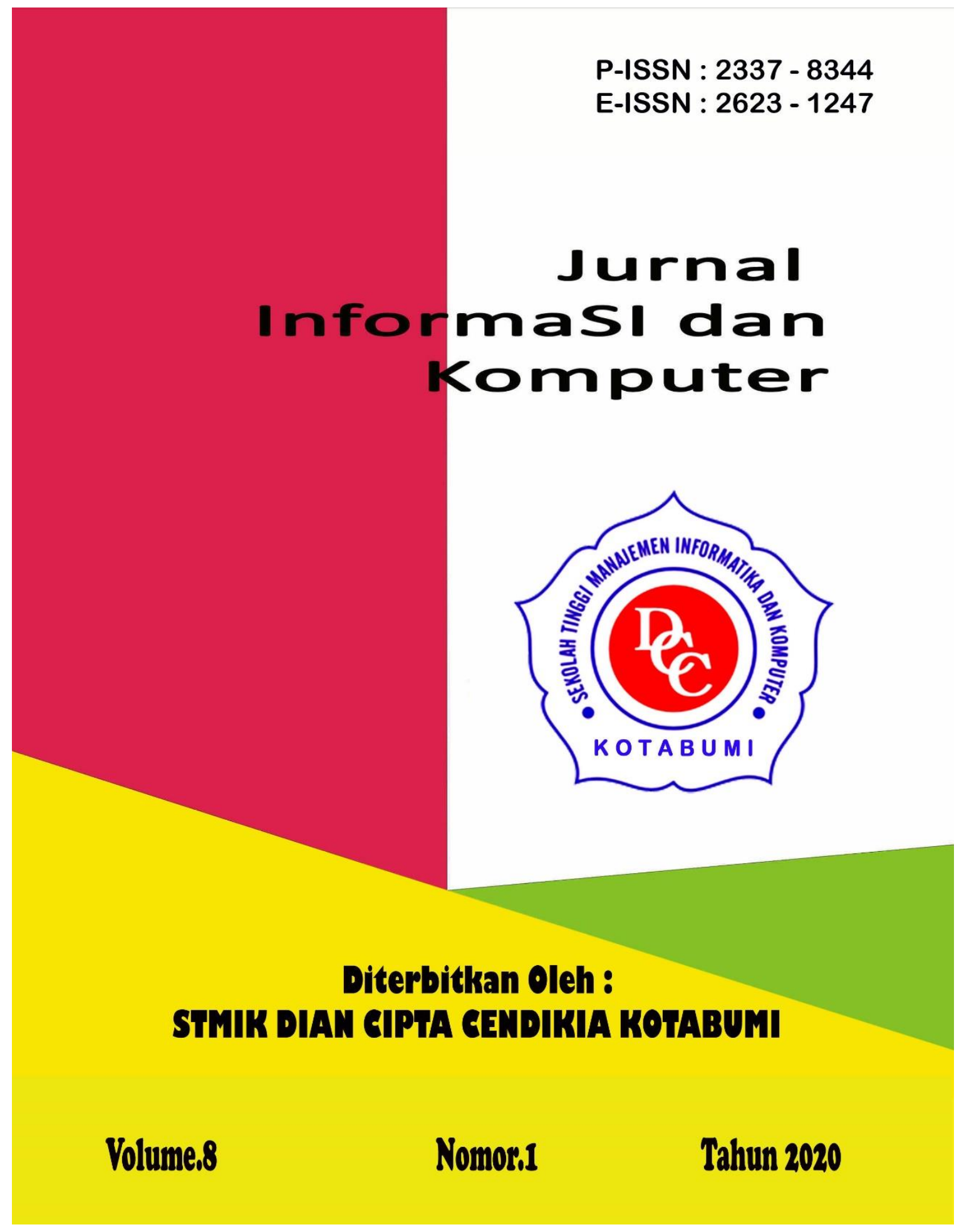




\section{Penerbit:}

STMIK DIAN CIPTA CENDIKIA KOTABUMI

Bekerjasama dengan LPPM STMIK DCC Kotabumi

Hak atas naskah/tulisan tetap berada pada penulis, isi diluar tanggung jawab

Penerbit dan Dewan Penyunting

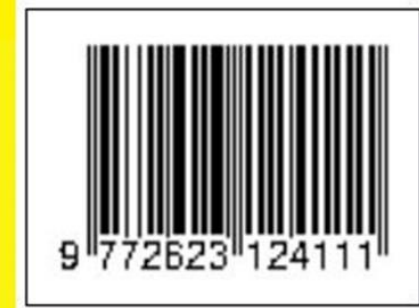




\section{PENGANTAR REDAKSI}

Puji syukur dipanjatkan kehadirat Tuhan Yang Maha Esa, atas karunia dan limpahan rahmatNYA jualah Jurnal Informatika dan komputer (InfoKom) STMIK Dian Cipta Cendikia Kotabumi ini dapat terwujud.Jurnal Informatika dan Komputer (InfoKom) yang terbit dua (2) kali dalam setahun ini merupakan suatu wadah untuk penyebar luasan hasil-hasil penelitian, studi pustaka, karya ilmiah yangberkaitan dengan Informatika dan Komputer khususnya bagi dosen-dosen STMIK Dian Cipta Cendikia Kotabumi serta umumnya para cendikiawan, praktisi, peneliti ilmu Informatika dan Komputer.

Harapan, dengan diterbitkannya Jurnal Informatika dan Komputer (InfoKom) ini sebagai salah satu bentuk sumbangan pemikiran dalam pengembangan ilmu informatika dan komputer yang berkaitan dengan kajian-kajian di bidang tekhnologi Informatik, Komunikasi Data dan Jaringan Komputer, perancangan dan Rekayasa Perangkat Lunak, serta ilmu-ilmu yang terkait dengan bidang Informatika dan Komputer lainnya.

Berkenaan dengan harapan tersebut, kepada para peneliti, dosen dan praktisi yang memiliki hasil-hasil penelitian, kajian pustaka, karya ilmiah dalam bidang tersebut diatas, dengan bangga redaksi Jurnal Informatika dan Komputer (JIK) menerima naskah ringkasan untuk dimuat pada jurnal Informatika dan Komputer (InfoKom) STMIK Dian Cipta Cendikia Kotabumi dengan berpedoman pada penulisan naskah jurnal sebagaimana dilampirkan pada halaman belakang (Bagian kulit dalam) buku jurnal ini.

Mutu dari suatu jurnal ilmiah tidak hanya ditentukan oleh para pengelolanya saja, tetapi para penulis dan pembaca jualah yang mempunyai peranan besar dalam meningkatkan mutu jurnal Informatika dan Komputer ini. Merujuk pada realita ini kamu sangat mengharapkan peran aktif dari peneliti untuk bersama-sama menjaga dan memelihara keberlangsungan dari jurnal Informatika dan Komputer STMIK Dian Cipta Cendikia Kotabumi ini. Yang juga tidak kalah pentingnya dari partisipasi tersebut diatas, adalah saran dan kritik yang membangun dari pembaca yang budiman agar kiranya dapat disampaikan langsung kepada redaksi JIK. Saran dan kritik yang membangun akan dijadikan masukan dan pertimbangan yang sangat berarti guna peningkatan mutu dan kualitas Jurnal Informatika dan Komputer STMIK Dian Cipta Cendikia Kotabumi.

Tak lupa diucapkan terima kasih yang tak terhingga atas perhatian dan kerjasama dari semua pihak yang tak dapat disebutkan satu persatu hingga dapat diterbitkan nya Jurnal Informatika dan Komputer (InfoKom) STMIK Dian Cipta Cendikia Kotabumi. Semoga apa yang telah diperbuat untuk kebaikan akan menjadi amal ibadah, amin.

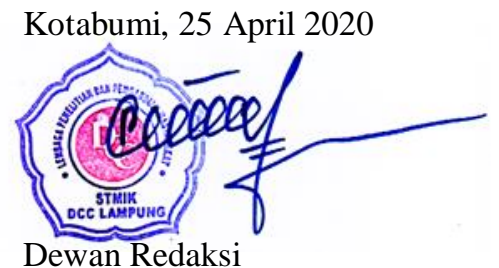




\section{JURNAL INFORMASI DAN KOMPUTER}

Volume 8 Nomor 1 April 2020

Jurnal Informasi dan Komputer merupakan Sarana informasi ilmu pengetahuan, Tekhnologi dan Komunikasi yang berupa hasil penelitian, tulisan ilmiah, Ataupun studi pustaka. Jurnal ini terbit dua kali setahun pada bulan April dan Oktober. Berisi hasil penelitian ilmiah di bidang informatika yang bertujuan untuk menghubungkan adanya kesenjangan antar kemajuan teknologi dan hasil penelitian. Jurnal ini di terbitkan pertama kali pada tahun 2013.

Penanggung Jawab:

Ketua STMIK Dian Cipta Cendikia

Kotabumi

\section{Pembina:}

Ketua STMIK Dian Cipta Cendikia

Kotabumi

Ketua Lembaga Penelitian STMIK Dian

Cipta Cendikia Kotabumi

\section{Pimpinan Redaksi}

Dwi Marisa Efendi,.S.Kom.,M.Ti

\section{Redaksi pelaksana}

Rustam,.S.Kom,.M.Ti (STMIK Dian

Cipta Cendikia Kotabumi)

Nurmayanti M.Kom (STMIK Dian

Cipta Cendikia Kotabumi)

Sukatmi,.S.Kom., M.Kom (AMIK DCC

Bandar Lampung)

Sampurna Dadi Riskiono,M.Kom

(Universitas Teknokrat Indonesia)

Ifo Wahyu

Pratama,S.Kom.,M.Ti(AMIK MASTER

Lampung)

\section{Mitra Bestari}

Merri Parida.,M.Kom (STMIK Dian

Cipta Cendikia Kotabumi)

Amarudin,S.Kom.,M.Eng (Universitas

Teknokrat Indonesia)

Didi Susianto.,S.T.,M.Kom (AMIK

DCC Bandar Lampung)

Alhibarsyah.,S.T.,M.Kom (Stmik Tunas

Bangsa Bandar Lampung)

Kemal Farouq Mauladi

.,S.Kom.,M.Kom (Universitas Islam

Lamongan)

Agus Setiawan S.Pd.,M.Eng

(Universitas Muhammadiyah

Lamongan)

Penerbit : STMIK Dian Cipta Cendikia Kotabumi Bekerja Sama Dengan LPPM STMIK Dian Cipta Cendikia Kotabumi.

\section{Alamat Redaksi/Penerbit:}

Jl. Negara No. 3 Candimas Kotabumi

Lampung Utara

No Telpon/Fax 072423003

Email : 1ppm-stmik@dcc.ac.id 


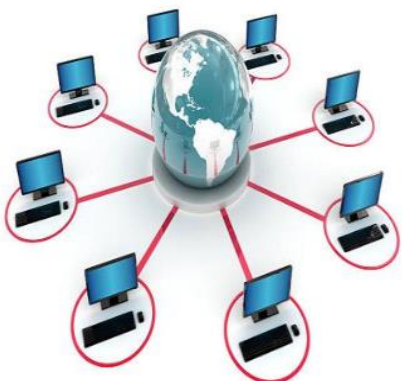 \\ JURNAL INFORMASI DAN KOMPUTER VOL. 8 NO. 1 THN. 2020}

\section{DAFTAR ISI}

\section{Halaman}

Sistem Pendukung Keputusan Penentuan Lahan Kopi Terbaik Dengan Metode

Ahp (Analytic Hierarchy Process)

Sidik Rahmatullah, Rendy Abdurahman (AMIKKOM Jogja,

STMIK Dian Cipta Cendikia Kotabumi)

Rancang Bangun Sistem Informasi Pada Program Pembangunan Pemberdayaan

Masyarakat Desa( P3md ) Berbasis Web Mobile

Ferly Ardhy, Firmansyah, Sidik Rahmatullah,(IIB Darma Jaya Bandar Lampung

STMIK Dian Cipta Cendikia Kotabumi, AMIKKOM Jogja)

Sistem Informasi Pengolahan Data Alumni Sekolah Menengah Atas (Sma)

Merri Parida, Nindiya Ova Rahmawati (AMIKKOM Jogja,

STMIK Dian Cipta Cendikia Kotabumi)

SISTEM INFORMASI GEOGRAFIS PUSKESMAS BESERTA SARANA

DAN PRASARANA BERBASIS WEB MOBILE

Nurmayanti, Windy Dwi Bahari (AMIKOM Jogja,

STMIK Dian Cipta Cendikia Kotabumi)

Rancang Bangun Sistem Informasi Konseling Untuk Sekolah Menengah Kejuruan

(Smk) Berbasis Website

Aliy Hafiz1, Galih Rakasiwi, Ifo Wahyu Pratama, Agus Komarudin,

Bambang Suparapto, Fathurrahman Kurniawan Ikhsan

(AMIK Dian Cipta Cendikia Bandar Lampung,

Universitas Nahdhatul Ulama Lampung, AMIK Dian Cipta Cendikia Pringsewu,

Universitas Mitra Indonesia, Lampung) .....

Sistem Pendukung Keputusan Pemilihan Driver Terbaik Menggunakan Metode

Weight Product (Wp)

Dina Lorenza, Pitrawati (STMIK Dian Cipta Cendikia Kotabumi

AMIK Dian Cipta Cendikia)

Rancang Bangun Sistem Informasi Pembayaran Mahasiswa

Darsin(Universitas Megou pak Tulang Bawang)

Sistem Informasi Geografis Bengkel Motor Honda Resmi Bandar Lampung

Sukatmi, Nuraini (AMIK Dian Cipta Cendikia Bandar Lampung).....

Sistem Pakar Diagnosa Penyakit Kulit Wajah Dengan Metode

Certainty Factor Pada Klinik Skin Rachel

Dwi Marisa Efendi, Putri Yulita Sari (IIB Darmajaya Bandar Lampung,

STMIK Dian Cipta Cendikia Kotabumi)..... 
Sistem Informasi Monitoring Siswa Pada Mts Al-Islamiah Bunut Kabupaten Pesawaran Yuli Syafitri ${ }^{2}$, Reni Astika ${ }^{1}$, Septian Hernando $^{3}$ AMIK Dian Cipta Cendikia

Aplikasi Kamus Bahasa Jepang Berbasis Mobile Android

Rustam $^{2}$, A Yanda Febry Pangestu ${ }^{2}$ Sistem Informasi, Teknologi Komputer ${ }^{1}$, IIB Darmajaya

Bandar Lampung ${ }^{2}$ STMIK Dian Cipta Cendikia Kotabumi 


\title{
APLIKASI KAMUS BAHASA JEPANG BERBASIS MOBILE ANDROID
}

\author{
Rustam $^{2}$ A Yanda Febry Pangestu ${ }^{2}$ \\ Sistem Informasi, Teknologi Komputer ${ }^{1}$, IIB Darmajaya Bandar Lampung ${ }^{2}$ \\ STMIK Dian Cipta Cendikia Kotabumi \\ E-mail : yandapangestu@gmail.com ${ }^{1}, \underline{\text { rustamdcc89@gmail.com }}^{2}$
}

\begin{abstract}
ABSTRAK
Kamus merupakan sejenis buku yang menerangkan makna kata kata maupun terjemahaan, tetapi berkembangnya era digital penggunaan kamus hanya sebatas buku secara fisik. Dengan di buatnya kamus offline berbasis android memudahkan pengguna maupun siswa yang keterbatasan dengan jaringan internet dan memudahkan juga bagi pengguna awal.

Dari permasalahan di atas maka penulis merancang sebuah aplikasi kamus bahasa jepang berbasis mobile android dengan menggunakan Applybuilder / MIT Inventor. Alat pengembangan sistem yang digunakan adalah Unified Modeling Language (UML) menggunakan use case diagram, diagram activity. Metode pengembangan sistem yang digunakan extreme programming, yang memiliki keunggulan pengembangan sistem yang lebih cepat dan proses pengembangan lebih responsive terhadap kebutuhan siswa atau pengguna. Data untuk penelitian ini dikumpulkan melalui teknik observasi atau pengamatan, wawancara dan studi pustaka. Data yang digunakan adalah berasal dari populasi dan sampel yang terdiri dari siswa dan pengguna.
\end{abstract}

Hasil dari penelitian maka diperoleh program aplikasi kamus bahasa jepang berbasis mobile android. Dengan sistem ini siswa / pengguna dapat dengan mudah mendapatkan hasil dari terjemahaan bahasa indonesia ke bahasa jepang dan sebaliknya tanpa harus menggunakan secara manual.

Kata kunci: kamus bahasa jepang, extreme programming, mobile android.

\section{ABSTRACTS}

The dictionary is a kind of book that explains the meaning of words and translation, but the development of the digital era the use of dictionaries is only limited to physical books. With the Android-based offline dictionary made it easier for users and students with limitations on the internet network and also makes it easier for beginning users.

From the above problems, the authors designed a Japanese android based mobile dictionary application using Applybuilder / MIT Inventor. The system development tool used is the Unified Modeling Language $(U M L)$ using use case diagrams, activity diagrams. The system development method used is extreme programming, which has the advantage of faster system development and a more responsive development process to the needs of students or users. Data for this research were collected through observation techniques, interviews, and literature study. The data used is derived from the population and sample consisting of students and users.

The results of the study obtained by the Japanese Android mobile dictionary based application program. With this system students / users can easily get results from translating Indonesian into Japanese and vice versa without having to use it manually.

Keywords: Japanese dictionary, extreme programming, mobile android. 


\section{PENDAhuluan}

Tanpa disadari kebutuhan manusia saat ini tidak terlepas dari teknologi informasi. Kini manusia dapat saling berinteraksi secara langsung dan mendapatkan informasi yang terkini, dimana batas antara jarak, ruang, dan waktu bukanlah penghalang bagi manusia untuk terus berkomunikasi dan mencari informasi. Dapat dilihat bahwa hampir setiap sarana pendidikan sudah banyak memiliki aplikasi pembelajaran modern. Oleh sebab itu dibutuhkan suatu sistem yang menghubungkan suatu perangkat pembelajaran yang baik, yang disebut dengan kamus pembelajaran. Banyaknya perangkat pembelajaran sekarang yang berbasis online dan berbagai macam dalam dunia pendidikan sehingga sulitnya mengakses jika tidak tersedia internet.

Di provinsi Lampung ini sangat sedikit dan mahir bahasa jepang, dari data Statistik Dinas Kependudukan Lampung 8.205.141 jiwa hanya sekitar 700 jiwa yang mampu berbahasa jepang dan digunakan hanya di berbagai sarana pendidikan tertentu saja, oleh karena itu pembuat ingin membangun suatu aplikasi yang bermanfaat bagi pendidikan di provinsi Lampung ini. Menurut Jeperson Hutahaean (2014:2), Sistem adalah suatu jaringan kerja dari prosedur-prosedur yang saling berhubungan berkumpul bersama-sama untuk melakukan kegiatan atau untuk melakukan sasaran yang tertentu[1].

Minim nya sumber daya manusia yang mampu berbahasa Jepang di Indonesia ini, terutama di provinsi Lampung, karena pesatnya ilmu teknologi dan bahasa asing masuk ke dalam negeri ini, creator ingin membuat suatu aplikasi pembelajaran berbasis mobile android offline, karena aplikasi ini tidak perlu mengakses dengan internet karena keterbatasan suatu jaringan yang ada dalam provinsi Lampung.

\section{METODOLOGI PENELITIAN}

Metode yang dilakukan oleh peneliti adalah metode Extreme Programming dan evaluasi, penelitian ini juga berbeda dengan penelitian di bidang lain.

\subsection{Perancangan Sistem}

Metode Extreme Programming adalah suatu model yang termasuk dalam pendekatan agile yang diperkenalkan oleh Kent Back. Menurut penjelasannya, definisi XP adalah sebagai berikut: "Extreme Programming (XP) adalah metode pengembangan software yang cepat, efisien, beresiko rendah, fleksibel, terprediksi, scientific, dan menyenangkan"[2].

Dalam metode Extreme Programming model ini cenderung menggunakan pendekatan Object - Oriented. Tahapan tahapan yang harus dilalui antara lain : Planning, Design, Coding, dan Testing. Sasaran Extreme Programming adalah tim yang dibentuk berukuran antara kecil sampai medium saja, tidak perlu menggunakan sebuah tim yang besar. Hal ini dimaksudkan untuk menghadapi requirements yang tidak jelas maupun terjadinya perubahan-perubahan requirements yang sangat cepat. Extreme Programming merupakan agile methods yang paling banyak digunakan dan menjadi sebuah pendekatan yang sangat terkenal.

\subsection{Variabel}

Variabel yang dibahas dalam penelitian ini adalah untuk mempermudah siswa dan masyarakat umum agar mudah dalam berbahasa asing ( Jepang ) dengan menggunakan aplikasi pembelajaran berbasis mobile android offline dengan mudah dan cepat.

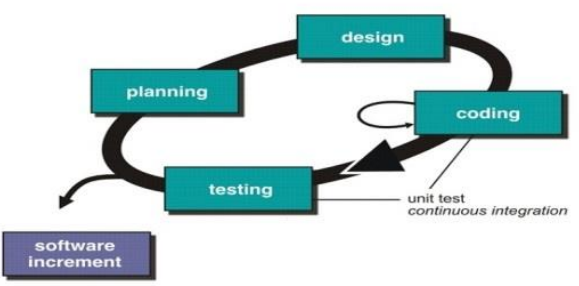

Gambar 2. Tahapan Extreme Programming

\subsection{Planning}

Planning adalah pemilihan atau penetapan tujuan organisasi dan penentuan strategi, kebijaksanaan, proyek, program, prosedur, metode, sistem, anggaran dan standar yang 
dibutuhkan untuk mencapai tujuan. Disini peneliti akan membuat suatu rencana terlebih dahulu agar dapat mengetahui apa yang dibutuhkan oleh siswa atau pengguna lainnya dan melakukan uji coba aplikasi kamus bahasa indonesia jepang ini sebagai sampel apakah berguna untuk perkembangan saat ini. Menurut L. Whitten, Jeffrey , Lonnie D. Bentley, Kevin C. Ditman (2004).[4]

\subsection{Design}

Peneliti akan melakukan rancangan aplikasi tersebut, kegiatan ini merupakan proses agar peneliti dapat merancang suatu media terjemahaan kamus bahasa indonesia jepang ,tampilan tentang aplikasi, fungsi dari aplikasi dan profil tentang pembuat aplikasi tersebut. Menurut Kristanto.2012 dan Jogiyanto, 2010. Analisis dan Desain Sistem Informasi. Graha Ilmu, Yogyakarta. [5]

\subsection{Coding}

Pada tahap ini peneliti akan membuatkan suatu rancangan aplikasi dengan menggunakan pengcodingan bloks dan drag, karena peneliti menggunakan aplikasi web terbuka yang bernama AppyBuilder / MIT App Inventor.

\subsection{Testing}

Pada tahap testing ini peneliti mencoba apakah aplikasi ini berhasil atau tidak dan melakukan uji coba langsung kepada siswa atau pengguna.

\subsection{Menguji Sistem}

Setelah sistem sudah menjadi suatu software yang siap pakai, maka software harus di tes dahulu sebelum digunakan. Hal ini bertujuan untuk meminimalisirkan kesalahan software tersebut.

\subsection{Penggunaan Sistem}

Perangkat Lunak / Software yang telah diuji dan diterima klien / pelanggan siap digunakan.

\subsection{Tempat dan Waktu Penelitian}

Penelitian akan di laksanakan di Sekolah Sekolah lebih tepatnya di SMP IT Al Farabi Pesawaran Lampung. Waktu penelitian akan di laksanakan dari tanggal 1 Maret 2019 sampai 30 Juni 2019.

\subsection{Populasi Sampel}

Populasi merupakan wilayah generalisasi yang terdiri dari obyek, subyek yang memiliki kuantitas dan karakteristik tertentu yang ditetapkan oleh peneliti untuk dipelajari dan kemudian ditarik kesimpulannya., populasi dalam penelitian ini adalah Siswa dan Masyarakat.

Sampel adalah sebagian dari jumlah dan karakteristik yang dimiliki oleh populasi, karena peneliti menggunakan teknik pengumpulan data berupa pengamatan langsung atau observasi non sistematis maka tidak digunakannya instrument penelitian yang digunakan adalah catatan yang diambil seelama peneliti melakukan di tempat penelitian dan beberapa diambil dari website yang berkaitan dengan penelitian dan juga beberapa dari literature yang relevan dengan penelitian. Pada penelitian ini pengambilan sampel yang di maksud adalah pengambilan sampel Siswa dan masyarakat sebagai pengguna aplikasi tersebut.)

\section{HASIL DAN PEMBAHASAN}

\subsection{Perangkat Keras ( Hardware )}

Perangkat keras yang dibutuhkan oleh peneliti adalah sebuah komputer / laptop sebagai media atau wadah dalam membuat suatu program aplikasi tersebut, dan menggunakan kamus fisik sebagai bahan referensi oleh Gading Dani Bao (2018). Kamus Mahir 3 Bahasa Indonesia Inggris Jepang Bantul, Banguntatap, Yogyakarta. [6]

\subsection{Perangkat Lunak ( Software )}

Perangkat lunak / tools yang dibutuhkan oleh peneliti adalah aplikasi MIT App Inventor / Apply Builder, aplikasi berbasis web open source yang awalnya dikembangkan oleh Google, dan saat ini dikelola oleh Massachusetts Institute of Technology (MIT). App Inventor 
memungkinkan pengguna baru untuk memprogram komputer untuk menciptakan aplikasi perangkat lunak bagi sistem operasi Android. App Inventor ini menggunakan antarmuka grafis, serupa dengan antarmuka pengguna pada Scratch, yang memungkinkan pengguna men-drag-anddrop objek visual untuk menciptakan aplikasi yang bisa dijalankan pada perangkat Android. Begitupun dengan coding, kita tidak perlu menulis kode program yang amat sangat panjang, cukup dengan men-dragand-drop seperti halnya menyusun puzzle. Appybuilder adalah Proyek ini dimulai pada bulan April 2010 oleh dua insinyur komputer Daniele Pelleri dan Luigi Giglio, yang membuka kantor pertama mereka di Milan, Italia, diikuti oleh kantor cabang di Catania. Mereka memperoleh pembiayaan dari pemodal ventura Massimiliano Magrini (Annapurna Ventures CEO) dan Mario Mariani (The Net Value CEO). Pada 2012.[3]

\subsection{Perangkat Pikir ( Brainware )}

Perangkat pikir yang dibutuhkan adalah Programmer karena Progammer Seseorang yang memiliki kemampuan dan keahlian dalam menguasai salah satu atau lebih bahasa pemograman dalam dunia komputerisasi. Progammer bertugas untuk membuat dan mempersiapkan programprogram yang dapat mendukung sistem komputer yang akan atau telah dirancang. Progammer penting jika saja terjadi hack terhadap database perusahaan.

\subsection{Hasil Program}

\subsubsection{Design Aplikasi}

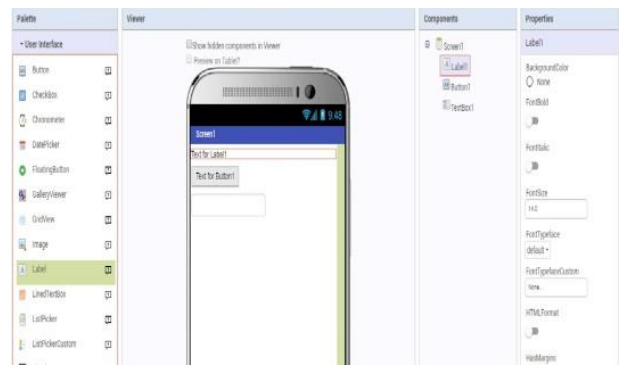

Gambar 8. Tampilan design aplikasi
Memasukan design Label untuk penulisan subject nama bahasa indonesia dan jepang Lalu masukan design textbox untuk memasukan kata yang ingin di arti kan, lalu design button berfungsi untuk mengklik program tersebut. Lalu design TinyDB berfungsi untuk mengkaitkan pengcodingan dalam program tersebut.

\subsubsection{Pengkodingan dengan Blocks}

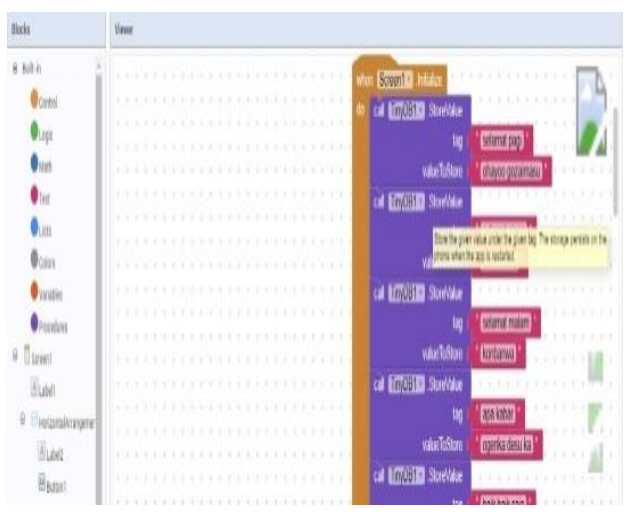

Gambar 9. Pengkodingan Dengan Blocks

Pada tahap ini kita memasukkan kode kode berbentuk blocks yang sekumpulan program yang sudah di buat sedemikian rupa yang bertujuan agar menciptakan kemudahan bagi pengguna supaya aplikasi berjalan dengan lancar dan mudah di pahami.

\subsubsection{Tampilan Home aplikasi}

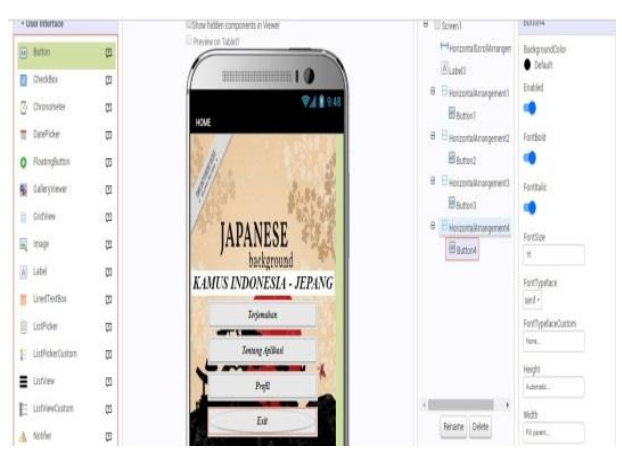

Gambar 10. Tampilan menu home

Pada tampilan di menu home ini siswa / pengguna dapat melihat atau memilih langsung tombol apa yang ingin di buka. 


\subsubsection{Tampilan Menu Terjemahaan}

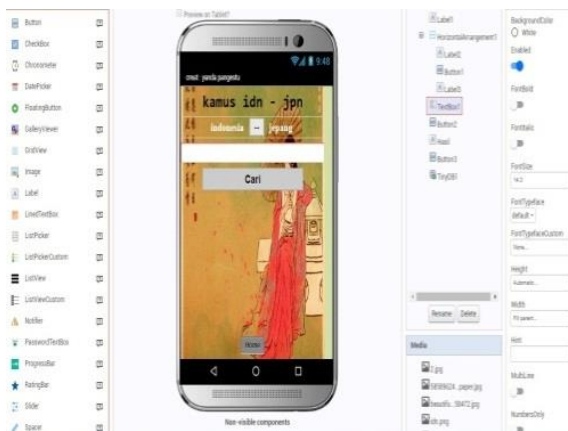

Gambar 11. Tampilan menu terjemahaan

Pada tampilan di menu Terjemahaan ini siswa / pengguna dapat melakukan pencarian bahasa yang ingin di cari baik itu bahasa indonesia ke bahasa jepang, ataupun sebaliknya.

\subsubsection{Tampilan menu tentang Aplikasi}

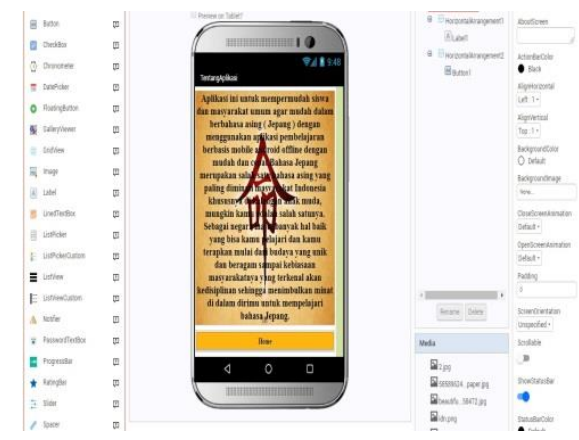

Gambar 12. Tampilan menu tentang aplikasi

Pada menu tentang aplikasi ini siswa / pengguna dapat mengetahui fungsi dari kegunaan aplikasi tersebut dan manfaat nya.

\subsubsection{Tampilan Menu Profil}
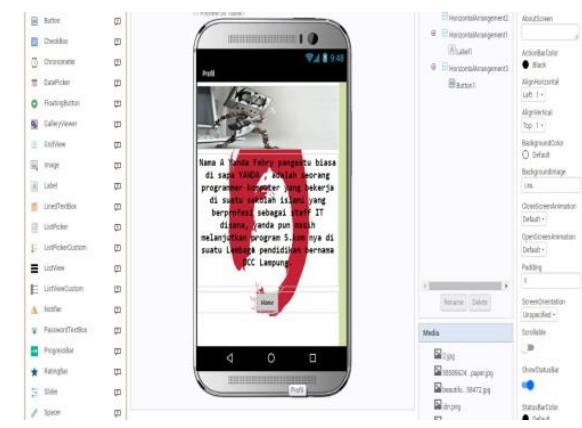

Gambar 13. Tampilan menu Profil

Pada tampilan menu profil ini siswa / pengguna dapat mengetahui biodata dari creator atau pembuat aplikasi tersebut.

\subsection{Keunggulan dan Kelemahan Sistem Appybuilder / MIT App Inventor}

Keunggulan Sistem ini sangat mudah di gunakan dan mudah di pelajari baik itu pengguna dasar dalam pemprograman untuk membuat suatu sistem aplikasi berbasis android.

Menggunakan web gratis dan tidak berbayar dalam membuat aplikasi ini.

Hanya menggunakan pengcodingan dengan blocks yang sudah dibuat sedemikian rupa sehingga tidak menggunakan rumus rumus tertentu.

\subsection{Kelemahan Sistem Appybuilder / MIT App Inventor}

Kelemahan Sistem ini harus menggunakan internet agar dapat membuat suatu program aplikasi berbasis android.

Keterbatasan Jumlah halaman sehingga pembuat tidak bisa membuat halaman yang banyak

Tanpa nama domain Profesional web builder gratis ini tidak memperbolehkan anda menggunakan URL sendiri.

\section{Kesimpulan}

Berdasarkan hasil analisis yang telah dilakukan oleh penulis mengenai aplikasi kamus bahasa jepang berbasis mobile android, penulis menarik beberapa kesimpulan.

1. Memudahkan siswa / pengguna untuk mengetahui arti dalam sebuah bahasa indonesia ke bahasa jepang dengan menggunakan aplikasi berbasis android secara gratis dan offline.

2. Dengan menggunakan metodologi Extreme Programming, penulis dapat mengatasi permasalahan yang terjadi selama pengembangan. 
3. Dengan menggunakan ApplyBuilder / MIT Inventor dapat melakukan perubahan kebutuhan perangkat lunak dan teratasi jika kesalahan yang terjadi seperti error atau bug dapat ditemukan dan diperbaiki selama tahapan pengembangan.

\section{Daftar Pustaka}

[1] Jeperson Hutahaean, P. W. (2014). Perancangan dan Implementasi Berbasis Mobile Android Aplikasi toko Online dengan Customer. Internasional

Conference on Automation, Cognitive Science,

[2] Ken Back ( 2016 ) "Extreme Programming (XP) adalah metode pengembangan software yang cepat, efisien, beresiko rendah, fleksibel, terprediksi, scientific, dan menyenangkan"

[3] Massimiliano Magrini ( Annapurna Ventures $C E O$ ) Hukum Pengenalan Aplikasi Mobile Android, 2012,

[4] L. Whitten, Jeffrey , Lonnie D. Bentley, Kevin C. Ditman (2004). Metode Design dan Analisis Sistem Edisi 6. Yogyakarta.

[5] Jogiyanto, 2010. Analisis dan Desain Sistem Informasi, Edisi IV, Andi Offset,. Yogyakarta.

[5] Kristanto.2012. Analisis dan Desain Sistem Informasi. Graha Ilmu, Yogyakarta.

[6] Gading Dani Bao (2018). Kamus Mahir 3 Bahasa Indonesia Inggris Jepang Bantul, Banguntatap, Yogyakarta.

[7] Supriyanto, Supriyanto. "Rancang Bangun Aplikasi Resep Masakan Berbasis Android." Jurnal Informasi Dan Komputer 7.1 (2019): 83-89.

Efendi, Dwi Marisa, Muhammad Bayu, and Joni Darsyah.

\section{"Sistem Informasi \\ Geografis Lokasi Kos}

[8] Dan Penginapan Berbasis Web Pada Wilayah Kotabumi Kabupaten Lampung Utara." Jurnal Informasi Dan Komputer 6.2 (2018): 1-10. 